\title{
The Physiologic Basis and Clinical Outcomes of Combined Impella and Veno-Arterial Extracorporeal Membrane Oxygenation Support in Cardiogenic Shock
}

Hoong Sern Lim

Received: April 15, 2020 / Published online: May 18, 2020 (C) The Author(s) 2020

\section{ABSTRACT}

Veno-arterial extracorporeal membrane oxygenation (VA-ECMO) provides effective hemodynamic support in cardiogenic shock, but in some cases may be complicated by left ventricular (LV) distension and pulmonary edema. The Impella, a catheter-mounted microaxial pump has been used to unload the LV. Recent studies have compared the clinical outcomes of VAECMO to the combination of Impella and VAECMO. The purpose of this review is threefold: firstly, to discuss the physiological effects of Impella support in addition to VA-ECMO, secondly to review published studies on the outcome of this combined support, and thirdly to provide a practical overview of the approach to combining Impella and VA-ECMO.

Keywords: Cardiogenic shock; Extracorporeal membrane oxygenation; Physiology

Digital Features To view digital features for this article go to https://doi.org/10.6084/m9.figshare.12213347.

Electronic supplementary material The online version of this article (https://doi.org/10.1007/s40119020-00175-6) contains supplementary material, which is available to authorized users.

H. S. Lim $(\bowtie)$

University Hospital Birmingham, Edgbaston,

Birmingham, UK

e-mail: sern.lim@uhb.nhs.uk

\section{Key Summary Points}

Left ventricular distension is a recognized complication of VA-ECMO support.

Impella is an effective venting or decompression strategy during VA-ECMO support.

The hemodynamic effects of Impella differ from other left ventricular venting strategies.

\section{INTRODUCTION}

Peripheral VA-ECMO or extracorporeal life support (ECLS) provides effective hemodynamic support in cardiogenic shock. However, VAECMO modifies the normal hemodynamics in the lung and left ventricle, with consequent increase in left ventricular (LV) end-diastolic pressure, LV distension, and pulmonary edema in some patients. A number of LV 'venting' or 'decompression' strategies have been used with varying degrees of success to mitigate this increase in LV end-diastolic pressure (Table 1). The insertion of a left-sided Impella (2.5, CP or 5.0) is one such strategy. 
Table 1 Left ventricular venting strategies

Intra-aortic balloon pump

Left ventricular assist device (e.g.,: Impella $2.5, \mathrm{CP}$ or 5.0)

(Surgical) Left ventricular drainage

Retrograde trans-aortic catheter drainage

(Trans-septal) left atrial drainage

Pulmonary artery catheter drainage

Pulmonary venous drainage

The Impella class of devices consists of catheter-mounted microaxial pumps that function as an Archimedes-screw pump, aspirating blood from the left ventricle and expelling into the aorta. The concomitant use of Impella with VAECMO was first described by Vlasselaers and colleagues in 2006 in a 13-year old boy [1]. Since that case report, this Impella-VA-ECMO combination has been increasingly deployed in the management of cardiogenic shock [2,3]. The comparative physiology and outcomes of Impella versus VAECMO in patients with cardiogenic shock, the use of Impella in high-risk coronary intervention, or in the treatment of acute myocardial infarction have been extensively reviewed [4-8]. This review will focus on (i) the physiology of combined Impella-VA-ECMO support, (ii) the clinical outcomes with this combines mechanical circulatory support strategy, and (iii) the practical approach to the use of Impella-VA-ECMO. This article is based on previously conducted studies and does not contain any studies with human participants or animals performed by any of the authors.

\section{THE PHYSIOLOGY OF LV DISTENSION ON VA-ECMO}

The circulatory physiology of VA-ECMO has been reviewed previously [9]. VA-ECMO generates a non-physiological circulation that has different effects on the right (RV) and LV. Firstly, the VAECMO circuit competes with the RV for preload. Higher VA-ECMO flow deprives the RV of preload and reduces RV output and pulmonary blood flow. Clinically, the latter may be evidenced by the reduction in pulmonary artery pulse pressure and partial pressure of end-tidal carbon dioxide levels unless ventilation is significantly decreased.

Secondly, blood is delivered retrogradely into the aorta (typically via a return cannula in the femoral artery), which pressurizes the systemic circulation and increases hemodynamic load on the LV. In order to overcome the increased afterload to maintain the ejection, the LV must have sufficient intrinsic contractility or, if unable to attain sufficient contractility following initiation of VA-ECMO, must recruit preload.

A number of mechanisms may conspire to limit LV contractile response under VA-ECMO support: (i) The ventricle in end-stage heart failure may intrinsically only have limited contractile reserve due to alterations in beta -adrenoreceptor $^{-}$ signaling and intracellular calcium handling [10]; (ii) LV contractile function may be compromised by high VA-ECMO flow $[11,12]$, possibly due to LV distension and impaired myocardial blood flow; (iii) in the case of respiratory failure associated with persistent LV ejection, flow of poorly oxygenated blood to the coronary circulation may worsen myocardial ischemia (and hypoperfusion of the upper body-so-called differential hypoxemia, north-south syndrome, or harlequin syndrome) and contractile dysfunction; and (iv) be in a state of myocardial stunning due to prolonged cardiac arrest, even in the presence of adequate cardiopulmonary resuscitation.

Other factors can contribute to LV distention other than inadequate LV contractility. Since the aorta is pressurized, pre-existing aortic regurgitation may be exacerbated by VA-ECMO. In addition, continuous filling of the LV due to bronchial and, to a lesser extent, Thebesian blood flow contribute to LV distension.

At a given level of contractile function, the heart must recruit preload (increase end-diastolic volume) to maintain stroke volume in the face of increased afterload (Fig. 1a) [13]. However, there are limits to which LV preload can increase. The heart is constrained by an intrinsic limit in recruitable preload reserve. In addition, due to the non-linear diastolic pressure-volume relation, a small increase in LV diastolic volume in the setting of an already dilated LV, results in a disproportionately greater increase in end-diastolic pressure (and risk of pulmonary edema). 
A

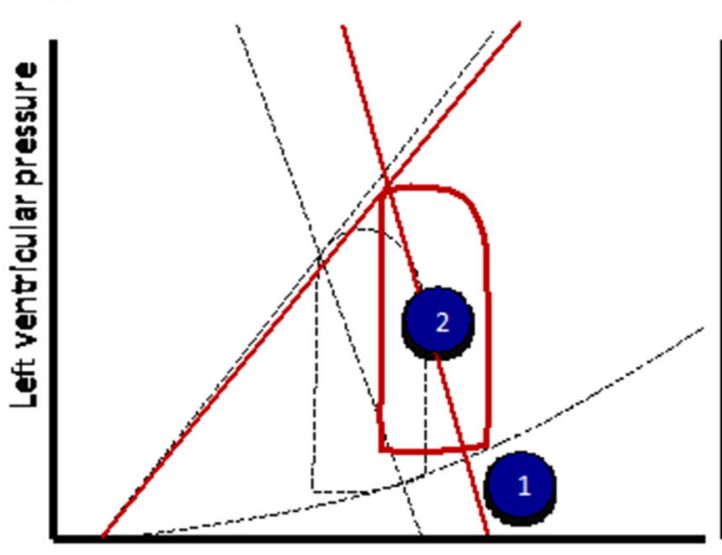

B

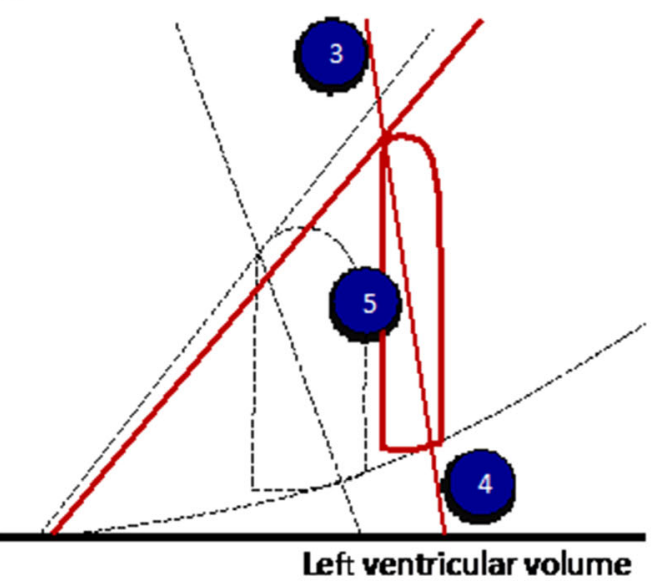

Fig. 1 a In the face of increased afterload, at constant level of contractility, the LV must increase diastolic volume (1) to recruit preload and maintain stroke volume (2). b Further increase in afterload (3), when the limit of

Exhaustion of preload reserve and limited contractile reserve renders the failing heart exquisitely sensitive to increases in afterload-a phenomenon that underpins the acute hemodynamic effects of vasodilators in heart failure with reduced ejection fraction; and the failure of $\mathrm{LV}$ ejection in response to acute increase in afterload associated with VA-ECMO (Fig. 1b).

The failure to sufficiently increase contractility or recruit preload to meet the increased afterload results in reduced LV stroke volume and diminished arterial pulse pressure, with concomitant increase in mean arterial blood pressure on VA-ECMO support. The simultaneous increase in LV volume and reduction in stroke volume reduces myocardial efficiency (the ratio of stroke work to myocardial oxygen consumption, the latter is approximated by the pressure-volume area) [14].

In this regard, VA-ECMO maintains pressure and blood flow in the systemic circulation, in contrast to the reduced pulmonary blood flow, effectively uncoupling the two circulations.

\section{THE PHYSIOLOGY OF IMPELLA AND VA-ECMO}

Case reports and case series have described significant reductions in filling pressures, LV preload reserve is reached (4) will lead to reduction in stroke volume, evident as narrowing of the width of the pressure-volume loop (5)

distension, and consequent improvement in cardiogenic pulmonary edema with Impella when deployed in combination with VA-ECMO in cardiogenic shock $[15,16]$. Cheng et al. [17] reported almost halving of pulmonary artery wedge pressure and reductions in central venous pressure and $\mathrm{LV}$ end-diastolic diameter $(7.8 \pm 1.4$ to $6.2 \pm 0.8 \mathrm{~cm}, p=0.001)$ in five patients with cardiogenic shock and LV distension related to VA-ECMO support (average Impella flow of $2.0 \pm 0.5 \mathrm{l} / \mathrm{min}$ ). These clinical observations are consistent with the physiological unloading effects of the Impella.

However, the unloading effect of Impella differs from other 'venting' strategies, such as pulmonary venous, pulmonary arterial, or trans-atrial septal drainage [18]. The latter strategies reduce LV end-diastolic volume and pressure (preload), thereby unloading the LV and diminish LV stroke volume. The reduction in LV stoke volume is directly related to drainage rate and may result in the loss of LV ejection (Fig. 2a). Hence, pulmonary venous, pulmonary arterial or trans-atrial septal drainage can reduce antegrade blood flow from the LV to the aorta. When these alternate strategies are used, special attention should be given to ensure that the aortic valve is opening to avoid stasis and thrombus formation in the $\mathrm{LV}$ and proximal aorta. 
A

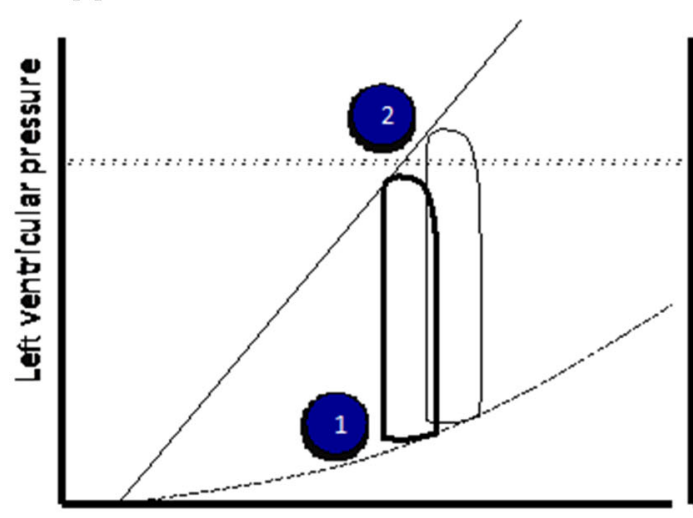

Fig. 2 a Pulmonary arterial, venous, or left atrial vent diminish LV volume (preload) with consequent reduction in LV end-diastolic pressure (1). Reduction in LV preload at unchanged contractility will reduce LV systolic pressure (2). The LV will fail to eject if LV systolic pressure fails to exceed aortic pressure (horizontal line). b The Impella

In contrast, the Impella continuously drains the LV and delivers the blood to the proximal aorta, thus maintaining flow from LV to the aorta even in the absence of LV ejection and a closed aortic valve. The continuous drainage of the LV abolishes the isovolumic phases, resulting in a triangular-shaped pressure-volume loop, reducing LV work, and unloading the LV (Fig. 2b). Furthermore, unlike left atrial or ventricular 'vent' drainage, which reduces LV ejection, the Impella contributes to total flow.

\section{CLINICAL OUTCOMES OF COMBINED IMPELLA AND VA- ECMO SUPPORT}

There are no prospective randomized trials that have compared venting strategies in VA-ECMO. Nevertheless, there are a number of (mostly single-center) retrospective registry studies that have evaluated the strategy of Impella and VAECMO in patients with cardiogenic shock (Table 2). Some reports have also inferred that this combination of Impella and VA-ECMO may facilitate LV recovery [19-21]. There are inherent limitations with these reports with considerable risk of biases-small number of patients,
B

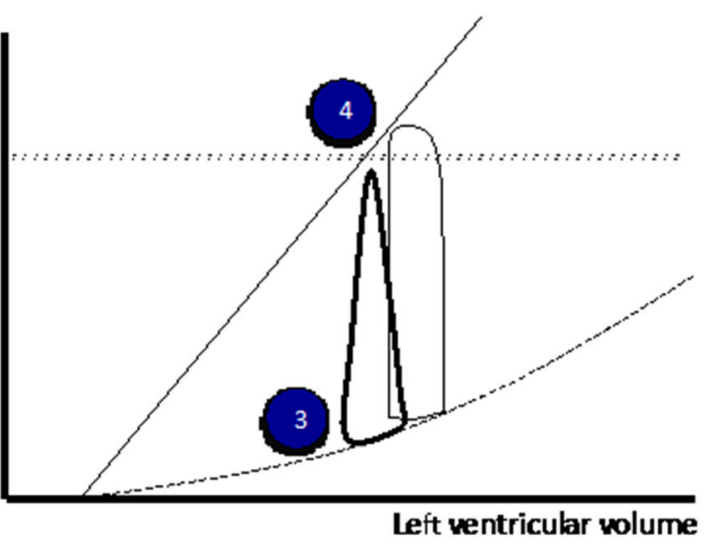

continuously drains from the LV, reducing LV volume and converts the pressure-volume loop into a triangular shape due to the loss of isovolumic phases (3). Left ventricular systolic pressure drops below aortic pressure and the LV fails to eject (4), but the Impella maintains LV output

the selection of patients, decision to vent, the use of Impella instead of other venting strategies, and management strategies of patients on VA-ECMO.

In a propensity matching study, Pappalardo et al. [22] compared Impella plus VA-ECMO to VA-ECMO alone in patients with cardiogenic shock of different etiologies. Overall in-hospital mortality is high (73\%), and the mortality in the VA-ECMO only group was significantly higher than the Impella and VA-ECMO group (48\%). However, there were significant differences in baseline characteristics between groups (the VAECMO only group was significantly more likely to have undergone cardiopulmonary resuscitation and had lower $\mathrm{pH}$ levels). Nevertheless, hospital survival remained significantly better in the propensity score-matched subgroup (Impella plus VA-ECMO group 48\% vs. VA ECMO alone $74 \%, p=0.04)$. In a separate study, Patel et al. [23] noted similar difference in survival between VA-ECMO alone compared to Impella plus VA-ECMO (30-day survival 22 vs. $43 \%$ respectively, $p=0.02$ ) in a cohort of 66 patients with cardiogenic shock of mixed etiologies. However, there were many differences in baseline characteristics between these groups, which limits the ability to draw any conclusions. 
Table 2 Outcome of combined Impella and VA ECMO support in cardiogenic shock

\begin{tabular}{|c|c|c|}
\hline Author & Description & Results \\
\hline \multirow{3}{*}{$\begin{array}{r}\text { Tepper } \\
2017\end{array}$} & Single-center study & 30-day survival $(p=0.42)$ : \\
\hline & 23 patients with Impella + VA ECMO & Impella + VA ECMO 43\% \\
\hline & $\begin{array}{l}\text { compared to } 22 \mathrm{VA} \text { ECMO + surgical } \\
\text { vent }\end{array}$ & VA ECMO + surgical vent $32 \%$ \\
\hline \multirow{7}{*}{$\begin{array}{l}\text { Pappalardo } \\
2017\end{array}$} & Multi-center study & Hospital mortality: \\
\hline & 34 Impella + VA ECMO compared to 123 & Impella + VA ECMO 47\% vs. VA ECMO 80\% $(p<0.001)$ \\
\hline & VA ECMO & Successful bridging to recovery or next therapy: \\
\hline & Propensity matched cohort & Impella + VA ECMO 68\% vs. VA ECMO $28 \%(p<0.001)$ \\
\hline & 21 Impella + VA ECMO compared to 42 & Propensity matched: \\
\hline & & Impella + VA ECMO 48\% vs. VA ECMO 74\% $(p=0.04)$ \\
\hline & & $\begin{array}{l}\text { Higher rates of hemolysis ( } 76 \text { vs. } 33 \%, p=0.004) \text { and CVVH } \\
(48 \text { vs. } 19 \%, p=0.02) \text { in the Impella }+ \text { VA ECMO group }\end{array}$ \\
\hline \multirow{4}{*}{$\begin{array}{l}\text { Colombier } \\
2018\end{array}$} & Single-center study & Median time to Impella $84(24-186)$ h \\
\hline & 31 patients with refractory shock despite & Median Impella support $8(5-10)$ days \\
\hline & VA ECMO and IABP & 30-day survival $53 \%$ \\
\hline & Median age 53 years, $74 \%$ males & HFREF independent risk factor for 30-day mortality \\
\hline \multirow{6}{*}{$\begin{array}{c}\text { Akanni } \\
2018\end{array}$} & Single-center study & 30-day survival $(p=0.913)$ : \\
\hline & 15 from Impella to Impella + VA ECMO & Impella to Impella + VA ECMO $46.7 \%$ \\
\hline & & VA ECMO to Impella + VA ECMO $42.9 \%$ \\
\hline & $\begin{array}{l}14 \text { from VA ECMO to Impella + VA } \\
\text { ECMO }\end{array}$ & VA ECMO alone $49 \%$ \\
\hline & Compared to 196 patients supported on VA & \\
\hline & ECMO & \\
\hline \multirow[t]{7}{*}{$\begin{array}{c}\text { Schrage } \\
2018\end{array}$} & Single-center study & $\begin{array}{l}\text { 21\% Impella first, } 19 \% \text { VA ECMO first, } 60 \% \text { implanted } \\
\text { simultaneously (59\% CPR) }\end{array}$ \\
\hline & 106 consecutive patients & Impella CP in $83(78 \%)$, Impella 2.5 in $23(22 \%)$ \\
\hline & 38 survivors and 68 non-survivors at 30 days & 12 patients (22\%) upgraded from Impella CP to Impella 5.0 \\
\hline & & Median duration of VA ECMO support: $6(3-10)$ days \\
\hline & & Median duration of Impella support: 6 (3-12) days \\
\hline & & $\begin{array}{l}12 \text { patients bridged to durable LVAD, no patients bridged to } \\
\text { transplantation }\end{array}$ \\
\hline & & 30 -day mortality $64 \%$ \\
\hline
\end{tabular}


Table 2 continued

\begin{tabular}{lll}
\hline Author & Description & Results \\
\hline Patel 2019 & Single-center study & Surgical venting in 21 (58\%) of VA ECMO patients \\
& $\begin{array}{l}30 \text { patients with Impella + VA ECMO } \\
\text { compared to 36 patients with VA ECMO }\end{array}$ & $\begin{array}{c}\text { 30-day survival: Impella + VA ECMO 43\% vs. VA ECMO } \\
22 \%=0.02)\end{array}$ \\
\hline
\end{tabular}

The timing of Impella support may be relevant. Akanni et al. [24] compared the outcomes of different sequences of support (Impella to Impella plus VA-ECMO, VA-ECMO to Impella plus VA-ECMO vs. VA-ECMO alone) in a cohort of patients with cardiogenic shock of various etiologies. The Impella was added after a median interval of 12 (4-26) h, and VA-ECMO was added to Impella after an interval of 7 (3-31) h. With this strategy of early escalation of support, there was no significant difference in 30-day survival between the groups (47 vs. 43 vs. $49 \%$, $p=0.913)$.

Colombier et al. [25] described their experience with Impella in 31 patients with VA-ECMO who had insufficient LV unloading with an intra-aortic balloon pump. The median time to Impella insertion was $84(24-186) \mathrm{h}$. Overall mortality at 30 days was $53 \%$, with significantly worse outcomes in patients with chronic heart failure. The physiology of patients with cardiogenic shock due to end-stage chronic heart failure differs from patients with acute myocardial infarction [26]. These patients with cardiogenic shock due to chronic heart failure are characterized by poor LV contractility, LV dilatation, often with co-existing mitral regurgitation and marked afterload sensitivity, which renders them particularly vulnerable to LV distension. These patients also tend to have greater degrees of $\mathrm{RV}$ dysfunction than in the acute myocardial infarction patients. It is possible that earlier Impella support may improve outcomes in these patients with end-stage heart failure.

Tepper et al. [27] compared Impella to a surgical vent in 45 patients with cardiogenic shock. Post-cardiotomy shock was more common in the surgical vent group, while acute myocardial infarction was significantly more common in the Impella group. Both Impella and surgical vent reduced pulmonary artery diastolic pressure although the change of central venous pressure was only significant in the Impella group. Despite comparable improvement in pulmonary artery diastolic pressure, radiological improvement in pulmonary edema was more common in the Impella group (65\%) compared to the surgical vent (24\%) group. There was no significant difference in 30-day survival, bleeding, or vascular complications. Some of the differences may be related to patient heterogeneity, small sample size, and differences in the surgical vent (cannula size and position) [28].

\section{COMPLICATIONS OF COMBINED IMPELLA AND VA-ECMO SUPPORT}

It is likely that the addition of Impella will also introduce Impella-related complications, but it is difficult to discern the clinical significance and contributions of VA-ECMO versus Impella to the adverse events in the absence of prospective randomized trials. In addition, the adverse event rates are confounded by the inherent biases in selecting the 'venting' strategies and implanter (center) experience with Impella and VA-ECMO.

Pappalardo et al. did note a higher incidence of hemolysis and renal failure in the Impella plus VA-ECMO group, but no significant difference in bleeding. However, these events are generally transient in nature, and may not compromise survival in the Impella group. Schrage et al. [29] reported their combined Impella plus VA-ECMO experience in 106 patients. Vascular complications requiring intervention, bleeding requiring intervention, 
hemolysis, and sepsis were reported in 34,25 , 47 , and $42 \%$ of patients, respectively.

Other studies of Impella have reported significant risks of complications, primarily related to vascular access, bleeding, and hemolysis. In the Impella-EUROSHOCK registry with Impella 2.5, which included 120 patients, major bleeding at the vascular access site, hemolysis, and pericardial tamponade occurred in 34 (28.6\%), nine $(7.5 \%)$, and two (1.7\%) patients, respectively [30]. In the Europella registry of 144 patients who underwent Impella 2.5 for highrisk PCI, rates of bleeding requiring transfusion or surgery and vascular complications were 6.2 and $4 \%$, respectively [31]. In a small randomized trial of 25 patients (12 with Impella), Seyfarth et al. [32] noted one acute limb ischemia requiring surgery, higher free hemoglobin, and greater packed red cells transfusions compared to IABP.

In contrast, Badiye et al. reported a significantly higher frequency of hemolysis, which occurred in the majority of patients on Impella support (62.5\% of 118 devices), with an average duration of support of $86 \mathrm{~h}$ [33]. Severe hemolysis resulting in acute renal failure has also been described [34]. Less common Impella-related complications include device failure due to kinking of the driveline (device failure) [35] and iatrogenic mitral regurgitation related to the positioning of the Impella in the mitral valve apparatus $[36,37]$. There do not appear to be any significant short or long-term detrimental effects on the aortic valve [38, 39].

\section{COMBINING IMPELLA AND VA- ECMO IN PRACTICE}

Cardiogenic shock is a complex syndrome with heterogenous clinical presentation, pathophysiology, etiology, and hemodynamic profile. Mechanical circulatory support (MCS) is a key element of cardiogenic shock care pathways [40]. Specifically, center-specific care pathways should define the triggers for initiation of MCS, the choice of MCS modality, and the escalation and management of MCS in patients with cardiogenic shock.
Impella and/or peripheral VA-ECMO are often the primary MCS modality of choice in critical cardiogenic shock, as they can be deployed rapidly. In either case, the adequacy of hemodynamic support and the adequacy of LV unloading need to monitored. The most direct means of guiding care through each of these stages of clinical decision-making is the use of a pulmonary artery catheter to measure central venous pressure, pulmonary capillary wedge pressure, and cardiac output. These critical measurements, when added to standard clinical measures such as blood pressure, lactate, urine output, and echocardiographic assessments of LV size, function, and aortic valve opening can help simultaneously optimize pharmacologic and guide escalation of mechanical circulatory support.

\section{Escalation of support from Impella CP}

The Impella $\mathrm{CP}$, which provides up to $3.5 \mathrm{l} / \mathrm{min}$ blood flow, can be inserted rapidly percutaneously, and is being increasingly deployed in patients with cardiogenic shock due to acute myocardial infarction. Impella 5.0, with its larger bore catheter and pump, has a blood flow capacity of $5.0 \mathrm{l} / \mathrm{min}$; however, this device generally requires surgical cutdowns for insertion. Thus, in many institutions, Impella CP is the first choice for support.

Right heart failure is an indication for escalating support from Impella CP. Rising central venous pressure (CVP), changes in CVP waveform (new ' $v$ ' waves and/or steep ' $y$ ' descent), diminishing pulmonary artery pulse pressure, and right ventricular dilatation on echocardiogram would be indicative of right heart failure. Typically, Impella flow would be limited by recurrent suction events in right heart failure, necessitating down-titration of Impella pump power level. The addition of VA ECMO to Impella CP is indicated in right heart failure.

In some cases, persistent low cardiac output may reflect inadequate support from Impella CP. Upgrading to Impella 5.0 may be indicated in the absence of right heart failure. 


\section{Addition of Impella to VA-ECMO}

Left ventricular distension and pulmonary edema is a complication of VA-ECMO, occurring in $30-68 \%$ of patients, at variable time from institution of VA-ECMO [41, 42]. A combination of arterial blood pressure monitoring, echocardiography (aortic valve opening, LV volume, spontaneous contrast and mitral regurgitation), pulmonary artery (wedge) pressure monitoring, partial pressure of end-tidal carbon dioxide levels and chest radiographs should be used routinely during VA-ECMO support for surveillance. Indication and threshold for LV decompression vary between centers, which reflect differences in practices in the absence of clinical trials. In general, indications for LV decompression include rising pulmonary artery pressures (and wedge pressure) and/or reducing arterial pulse pressure (LV ejection) in association with LV dilatation and/ or worsening pulmonary congestion on chest radiograph, or (ii) spontaneous contrast on echocardiography with limited or no aortic valve opening. We have adopted the routine insertion of Impella CP at the time of peripheral VA-ECMO support in Birmingham since 2016, a practice that is not unique to our center [31].

We have previously estimated the total systemic blood flow using the Fick principle during Impella and VA-ECMO support [43] [SUPPLEMENTARY MATERIAL]. The increase in transpulmonary blood flow is supported by the observed increase in partial pressure of end-tidal carbon dioxide, a finding that has been confirmed by other investigators [44].

\section{CONCLUSIONS}

Left ventricular distension and pulmonary edema are recognized complications of the abnormal circulatory physiology associated with VA-ECMO. The Impella left ventricular assist device effectively unloads the LV and relieves VA-ECMO-related LV distension. Unlike other venting strategies, the Impella also contributes to total blood flow. Despite the additional risks associated with Impella, some studies have reported better clinical outcomes with combined Impella and VA-ECMO support compared to VA-ECMO alone; and these findings will need to be confirmed in future prospective studies.

\section{ACKNOWLEDGEMENTS}

Funding. No funding or sponsorship was received for this study or publication of this article.

Authorship. All named authors meet the International Committee of Medical Journal Editors (ICMJE) criteria for authorship for this article, take responsibility for the integrity of the work as a whole, and have given their approval for this version to be published.

Disclosures. Hoong Sern Lim has nothing to disclose.

Compliance with Ethics Guidelines. This article is based on previously conducted studies and does not contain any studies with human participants or animals performed by any of the authors.

Data Availability. Data sharing is not applicable to this article as no datasets were generated or analyzed during the current study.

Open Access. This article is licensed under a Creative Commons Attribution-NonCommercial 4.0 International License, which permits any non-commercial use, sharing, adaptation, distribution and reproduction in any medium or format, as long as you give appropriate credit to the original author(s) and the source, provide a link to the Creative Commons licence, and indicate if changes were made. The images or other third party material in this article are included in the article's Creative Commons licence, unless indicated otherwise in a credit line to the material. If material is not included in the article's Creative Commons licence and your intended use is not permitted by statutory regulation or exceeds the permitted use, you will need to obtain 
permission directly from the copyright holder. To view a copy of this licence, visit http:// creativecommons.org/licenses/by-nc/4.0/.

\section{REFERENCES}

1. Vlasselaers D, Desmet M, Desmet L, Meyns B, Dens J. Ventricular unloading with a miniature axial flow pump in combination with extracorporeal membrane oxygenation. Intensive Care Med. 2006;32: 329-33.

2. Mourad M, Gaudard P, De La Arena P, Eliet J, Zeroual $\mathrm{N}$, Rouvière $\mathrm{P}$, et al. Circulatory support with extracorporeal membrane oxygenation and/or Impella for cardiogenic shock during myocardial infarction. ASAIO J. 2018;64:708-14.

3. Shah M, Patnaik S, Patel B, Ram P, Garg L, Agarwal $M$, et al. Trends in mechanical circulatory support use and hospital mortality among patients with acute myocardial infarction and non-infarction related cardiogenic shock in the United States. Clin Res Cardiol. 2018;107:287-303.

4. Kawashima D, Gojo S, Nishimura T, Itoda Y, Kitahori K, Motomura N, Morota T, Murakami A, Takamoto S, Kyo S, Ono $M$. Left ventricular mechanical support with Impella provides more ventricular unloading in heart failure than extracorporeal membrane oxygenation. ASAIO J. 2011;57:169-76.

5. Lamarche Y, Cheung A, Ignaszewski A, Higgins J, Kaan A, Griesdale DE, Moss R. Comparative outcomes in cardiogenic shock patients managed with Impella microacial pump or extracorporeal life support. J Thorac Cardiovasc Surg. 2011;142:60-5.

6. Chamogeorgakis T, Rafael A, Shafii AE, Nagpal D, Pokersnik JA, Gonzalez-Stawinski GV. Which is better: a miniaturized percutaneous ventricular assist device or extracorporeal membrane oxygenation for patients with cardiogenic shock? ASAIO J. 2013;59:607-11.

7. Schiller P, Hellgren L, Vikholm P. Survival after refractory cardiogenic shock is comparable in patients with Impella and veno-arterial extracorporeal membrane oxygenation when adjusted for SAVE score. Eur Heart J Acute Cardiovasc Care. 2018;8:2048872618799745. https://doi.org/10. $1177 / 2048872618799745$ [Epub ahead of print].

8. Myat A, Patel N, Tehrani S, Banning AP, Redwood SR, Bhatt DL. Percutaneous circulatory assist devices for high-risk coronary intervention. J Am Coll Cardiol Intv. 2015;8:229-44.
9. Lim HS, Howell N, Ranasinghe A. Extracorporeal life support: physiological concepts and clinical outcomes. J Card Fail. 2017;23:181-96.

10. Kobayashi M, Izawa H, Cheng XW, Asano H, Hirashiki A, Unno K, et al. Dobutamine stress testing as a diagnostic tool for evaluation of myocardial contractile reserve in asymptomatic or mildly symptomatic patients with dilated cardiomyopathy. JACC Cardiovasc Imaging. 2008;1:718-26.

11. Pyles LA, Gustafson RA, Fortney J, Einzig S. Extracorporeal membrane oxygenation induced cardiac dysfunction in newborn lambs. J Cardiovasc Transl Res. 2010;3:625-34.

12. Ostadal P, Micek M, Kruger A, Hala P, Lacko S, Mates $\mathrm{M}$, et al. Increasing venoarterial extracorporeal membrane oxygenation flow negatively affects left ventricular performance in a porcine model of cardiogenic shock. J Transl Med. 2015;13:266.

13. Ross J Jr. Afterload mismatch and preload reserve: a conceptual framework for the analysis of ventricular function. Prog Cardiovasc Dis. 1976;18:255-64.

14. Burkhoff D, Sayer G, Doshi D, Uriel N. Hemodynamics of mechanical circulatory support. J Am Coll Cardiol. 2015;66:2663-744.

15. Ise $H$, Kitahara $H$, Aubin $H$, Saeed $D$, Westenfeld $R$, Akhyari $\mathrm{P}$, et al. Additional unloading of the left ventricle using the Impella LP 2.5 during extracorporeal life support in cases of pulmonary congestion. J Surg Case Rep. 2018;11:302.

16. Jouan J, Grinda JM, Bricourt MO, Cholley B, Fabiani JN. Successful left ventricular decompression following peripheral extracorporeal membrane oxygenation by percutaneous placement of a microaxial flow pump. J Heart Lung Transpl. 2010;29:135-6.

17. Cheng A, Swartz MF, Massey HT. Impella to unload the left ventricle during peripheral extracorporeal membrane oxygenation. ASAIO J. 2013;59:533-6.

18. Donker DW, Brodie D, Henriques JPS, Broome M. Left ventricular unloading during veno-arterial ECMO: a simulation study. ASAIO. 2019;65:11-20.

19. Koeckert MS, Jorde UP, Naka Y, Moses JW, Takayama H. Impella LP 2.5 for left ventricular unloading during venoarterial extracorporeal membrane oxygenation support. J Card Surg. 2011;26:666-8.

20. Chaparro SV, Badheka A, Marzouka GR, Tanawuttiwat T, Ahmed F, Sacher V, Pham SM. Combined use of Impella left ventricular assist device and extracorporeal membrane oxygenation as a bridge 
to recovery in fulminant myocarditis. ASAIO J. 2012;58:285-7.

21. Narain S, Paparcuri G, Fuhrman TM, Silverman RB, Peruzzi WT. Novel combination of Impella and extracorporeal membrane oxygenation as a bridge to full recovery in fulminant myocarditis. Case Rep Crit Care. 2012;2012:459296.

22. Pappalardo F, Schulte C, Pieri M, Schrage B, Contri $\mathrm{R}$, Soeffker $\mathrm{G}$, et al. Concomitant implantation of Impella on top of veno-arterial extracorporeal membrane oxygenation may improve survival of patients with cardiogenic shock. Eur J Heart Fail. 2017;19:404-12.

23. Patel SM, Lipinski J, Al-Kindi SG, Patel T, Saric P, Li $\mathrm{J}$, et al. Simultaneous venoarterial extracorporeal membrane oxygenation and percutaneous left ventricular decompression therapy with Impella is associated with improved outcomes in refractory cardiogenic shock. ASAIO J. 2019;65:21-8.

24. Akanni OJ, Takeda K, Truby LK, Kurlansky PA, Chiuzan C, Han J, et al. EC-VAD: combined use of extracorporeal membrane oxygenation and percutaneous microaxial pump left ventricular assist device. ASAIO J. 2018;65:219-26.

25. Colombier S, Quessard A, Mastroianni C, Schmidt M, Amour M, Leprince P, Lebreton G. Benefits of Impella and peripheral veno-arterial extracorporeal life support alliance. ASAIO J. 2018. https://doi.org/ 10.1097/MAT.0000000000000922 [Epub ahead of print].

26. Lim HS, Howell N. Cardiogenic shock due to endstage heart failure and acute myocardial infarction: characteristics and outcome of temporary mechanical circulatory support. Shock. 2018;50: 167-72.

27. Tepper S, Masood MF, Baltazar Garcia M, Pisani M, Ewald GA, et al. Left ventricular unloading by Impella device versus surgical vent during extracorporeal life support. Ann Thorac Surg. 2017;104:861-7.

28. Formica F, D'Alessandro S, Avalli L. Is the Impella device really useful to unload the left ventricle during extracorporeal life support? Ann Thorac Surg. 2018;105:1861.

29. Schrage B, Burkhoff D, Rubsamen N, Becher PM, Schwarzi M, Bernhardt A, et al. Unloading of the left ventricle during venoarterial extracorporeal membrane oxygenation therapy in cardiogenic shock. J Am Coll Cardiol HF. 2018;6:1035-43.

30. Lauten A, Engstrom AE, Jung C, et al. Percutaneous left ventricular support with the Impella 2.5 assist device in acute cardiogenic shock: results of the
Impella EUROSHOCK registry. Circ Heart Fail. 2013;6:23-30.

31. Sjauw KD, Konorza T, Erbel R, Danna PL, Viecca M, Minden $\mathrm{HH}$, et al. Supported high-risk percutaneous coronary intervention with the Impella 2.5 device. the Europella registry. J Am Coll Cardiol. 2009;54:2430-4.

32. Seyfarth M, Sibbing D, Bauer I, Frohlich G, BottFlugel L, Byrne R, et al. A randomized clinical trial to evaluate the safety and efficacy of a percutaneous left ventricular assist device versus intra-aortic balloon pumping for treatment of cardiogenic shock caused by myocardial infarction. J Am Coll Cardiol. 2008;52:1584-8.

33. Badiye AP, Hernandez GA, Novoa I, Chaparro SV. Incidence of hemolysis in patients with cardiogenic shock treated with Impella percutaneous left ventricular assist device. ASAIO J. 2016;62:11-4.

34. Kummerfeldt CE, Toma A, Badheka AO, Azzam I, Andrews D, Alfonso C, Chaparro SV. Severe hemolytic anemia and acute kidney injury after percutaneous continuous-flow ventricular assistance. Circ Heart Fail. 2011;4:e20-e2222.

35. Beurtheret $S$, Mordant $P$, Pavie A, Leprince P. Impella and extracorporeal membrane oxygenation: a demanding combination. ASAIO J. 2012;58:291-3.

36. Eftekhari A, Eiskjær H, Terkelsen CJ, Nielsen SL, Christiansen EH, Poulsen SH. Perforation of the anterior mitral leaflet after Impella LP 5.0 therapy in cardiogenic shock. Am J Cardiol. 2016;117: 1539-41.

37. Elhussein TA, Hutchison SJ. Acute mitral regurgitation: Unforeseen new complication of the Impella LP 5.0 ventricular assist device and review of literature. Heart Lung Circ. 2014;23:e100-e104104.

38. O’Neill WW, Kleiman NS, Moses J, Henriques JPS, Dixon S, Massaro J, et al. A prospective, randomized clinical trial of hemodynamic support with Impella 2.5 versus intra-aortic balloon pump in patients undergoing high-risk percutaneous coronary intervention. Circulation. 2012;126:1717-27.

39. Engstrom AE, Sjauw KD, Baan J, Remmelink M, Claessen BE, Kikkert WJ, et al. Long-term safety and sustained left ventricular recovery: long-term results of percutaneous left ventricular support with Impella LP 2.5 in ST-elevation myocardial infarction. Eurointervention. 2011;6:860-5.

40. Van Diepen S, Katz JN, Albert NM, Henry TD, Jacobs AK, Kapur NK, et al. Contemporary management of cardiogenic shock. A scientific statement from the American heart association. Circulation. 2017;136: e232-e268268. 
41. Truby LK, Takeda K, Mauro C, Yuzefpolskaya M, Garan AR, Kirtane AJ, et al. Incidence and implications of left ventricular distension during venoarterial extracorporeal membrane oxygenation support. ASAIO J. 2017;63:257-65.

42. Soleimani B, Pae WE. Management of left ventricular distension during peripheral extracorporeal membrane oxygenation for cardiogenic shock. Perfusion. 2012;27:326-31.
43. Lim HS. The effect of Impella CP on cardiopulmonary physiology during venoarterial extracorporeal membrane oxygenation support. Artif Organs. 2017;41:1109-12.

44. Eliet J, Gaudard P, Zeoual N, Rouviere P, Albat B, Mourad M, Colson PH. Effect of Impella during veno-arterial extracooporeal membrane oxygenation on pulmonary artery flow as assessed by endtidal carbon dioxide. ASAIO J. 2018;64:502-7. 